\title{
Prognostic impact of vascular invasion in differentiated thyroid carcinoma: a systematic review and meta-analysis
}

\author{
Huy Gia Vuong1,2, Tetsuo Kondo', Uyen N P Duong3, Thong Quang Pham², \\ Naoki Oishi ${ }^{1}$, Kunio Mochizuki ${ }^{1}$, Tadao Nakazawa ${ }^{1}$, Lewis Hassell ${ }^{4}$ and \\ Ryohei Katoh'
}

${ }^{1}$ Department of Pathology, University of Yamanashi, Yamanashi, Japan, ${ }^{2}$ Department of Pathology, Cho Ray Hospital, Ho Chi Minh City, Vietnam, 3Pham Ngoc Thach University of Medicine, Ho Chi Minh City, Vietnam, and ${ }^{4}$ Department of Pathology, University of Oklahoma Health Sciences Center, Oklahoma City, Oklahoma, USA
Correspondence should be addressed to T Kondo

Email

ktetsuo@yamanashi.ac.jp

\begin{abstract}
Background: The role of vascular invasion (VI) as a prognostic marker in thyroid cancer is continuously debated among investigators. In this systematic review and meta-analysis, we aimed to investigate the association of VI with tumor recurrence and patient mortality in differentiated thyroid cancers (DTCs).

Methods: We searched five electronic databases for cases of DTC matching our criteria. Data of tumor persistence, locoregional recurrence (LRR), distant recurrence (DR) and overall recurrence/persistence (RP) were extracted and pooled into odds ratios (OR) and corresponding $95 \%$ confidence intervals (Cls) using random effect model. Pooled hazard ratio (HR) for disease-specific survival (DSS) was calculated using random effect model weighted by inverse variance method. Publication bias was examined by using Egger's test and funnel plot.

Results: From 1650 studies, we included 26 studies comprising 11961 DTCs for meta-analyses. In DTC patients, we found significant associations of $\mathrm{VI}$ with tumor persistence $(\mathrm{OR}=2.75 ; 95 \% \mathrm{Cl}=1.46-5.18), \mathrm{LRR}(\mathrm{OR}=4.44 ; 95 \%$ $\mathrm{Cl}=2.94-6.71)$, DR $(\mathrm{OR}=5.08 ; 95 \% \mathrm{Cl}=2.95-8.75)$, overall $\mathrm{RP}(\mathrm{OR}=3.53 ; 95 \% \mathrm{Cl}=2.09-5.96)$ and worse DSS $(\mathrm{HR}=2.47$; $95 \% \mathrm{Cl}=1.45-4.21$ ). Our results also demonstrated that the presence of extensive $\mathrm{VI}$ is associated with a significantly higher risk for DR in follicular thyroid carcinomas as compared with focal VI.

Conclusion: Our study demonstrated a significant impact of VI on tumor recurrence and patient survival in DTC patients. The presence and extent of VI should be considered an adverse prognostic factor in DTCs.
\end{abstract}

\section{Introduction}

Thyroid carcinoma is the most common endocrine malignancy, and its incidence has been increasing over the years worldwide $(1,2)$. According to the World Health Organization (WHO) classification, thyroid cancer is classified into differentiated thyroid carcinoma (DTC), poorly differentiated thyroid carcinoma (PDTC) and undifferentiated thyroid carcinoma (UTC) (3). DTCs including papillary thyroid carcinoma (PTC), follicular thyroid carcinoma (FTC) and Hurthle cell carcinoma (HCC) account for 95\% of thyroid cancer and have
(C) 2017 European Society of Endocrinology Printed in Great Britain more favorable prognosis as compared with PDTCs and ATCs (3).

DTCs usually exhibit indolent behavior with a 10-year survival rate of approximately $90-95 \%(1,3,4)$. Various clinicopathological factors have been reported to affect the patient outcomes such as older age, male gender, large tumor size, nodal or distant metastasis (5). VI is not a common event in DTCs which ranged from $2.5 \%$ to $52 \%(6,7,8)$. The rate of VI is higher in FTC than in PTC which can explain why FTC metastasizes to distant organs

Published by Bioscientifica Ltd. 
more frequently than does PTC (7). The role of VI as a prognostic factor in DTC, however, remains controversial among literature studies $(7,9,10)$.

In the current study, we aimed to conduct a systematic review and meta-analysis of observational studies to determine the impact of VI on tumor recurrence and disease-related mortality in patients with DTC.

\section{Methods}

\section{Literature search}

We searched for relevant articles in five electronic databases including PubMed, ISI Web of Science, Scopus, World Health Organization Global Health Library (WHO GHL) and Virtual Health Library (VHL) from inception to February 2017. The search terms were the following: (papillary OR follicular OR Hurthle OR differentiated OR well-differentiated) AND thyroid AND (carcinoma OR cancer) AND (vascular OR intravascular OR angioinvasive). Potential studies were also found by reviewing the citations within the included publications and reviews. Our study strictly followed the recommendation of Preferred Reporting Items for Systematic Review and Meta-analysis (PRISMA) statement (11).

\section{Selection criteria and abstract screening}

We imported all search results from five electronic databases into Endnote (Thomson Reuters, PA, USA) and performed duplicate deletion. Two reviewers independently screened the titles and abstracts of included studies using the following inclusion criteria (i) retrospective or prospective observational studies and (ii) articles in which the authors investigated the association of VI with tumor RP or disease-related mortality in patients with DTC. We used the following criteria to exclude studies: (i) studies only reporting data on lymphatic invasion and had no data for VI, (ii) articles in which PDTCs or ATCs were included and extracted data of DTC not separately segregatable, (iii) review, (iv) case report, (v) conference, poster, proceeding paper, book, thesis and (vi) duplicated articles. Disagreements between two reviewers were resolved by discussion and consensus.

\section{Full-text screening and data extraction}

Full text of all potential articles was consecutively downloaded and screened independently by two reviewers. Relevant data were extracted into a predefined data extraction form. We extracted the following data: institution, city, country, publication year, surgical time period, study design, number of events of tumor recurrence (LRR, DR, tumor persistence, overall RP) and disease-related death. Data of survival outcomes (DSS) and follow-up duration were also collected, if available. Disagreements between two reviewers were resolved again by discussion and consensus. In cases of insufficient data in the original papers or unpublished data, we tried to obtain potential data by contacting the authors via email.

\section{Quality assessment and risk of bias analysis}

We assessed the methodologic quality of included studies based on the Newcastle-Ottawa Scale (NOS) for quality of cohort studies in our meta-analyses (12). Stars were awarded for each cohort study (maximum nine stars) based on a developed checklist (12). In the second domain of outcome category, we awarded one star if the study had a median time of follow-up longer than five years, which was considered long enough for tumor recurrence and mortality to occur. In the last domain of outcome category, studies with the follow-up rate $\geq 80 \%$ or description of those lost suggesting no difference from those followed were awarded one star. Studies awarded at least six stars were considered moderate- to high-quality studies and those with a NOS value of less than six were regarded low-quality studies.

\section{Data analysis}

We used Review Manager version 5.3 (Cochrane Collaborative, Oxford, UK) to analyze data. We calculated the pooled estimates of OR and its 95\% CI to examine the association of vascular invasion with tumor recurrence (LRR, DR, tumor persistence and overall RP) by using random-effect modeling. We excluded the studies from the meta-analyses where there were no events in both arms because such studies do not provide any indication of either the direction or magnitude of the effect (13). Because survival rates at specific time points are known to be incompatible for meta-analyses of time-to-event data, pooled hazard ratio (HR) for DSS was calculated using the random model effect weighted by inverse variance method. HR and its 95\% CI were directly collected from the original articles or indirectly estimated from Kaplan-Meier curves using the methods by Tierney et al. (14) Heterogeneity across studies was quantified by 
the $I^{2}$ statistic, which measures the percentage of total variation across studies (15). Degree of heterogeneity across studies was classified as low, moderate and high with value of $<25,25-50$ and $>50 \%$, respectively (16). Sources of heterogeneity were examined by using (i) subgroup analysis (PTC and FTC) and (ii) sensitivity analysis performed by excluding each of the included studies one at a time. Presence of publication bias was examined using Egger's regression test and funnel plot, investigated by MAVIS version 1.1.2-a R package (17). A $P$ value less than 0.05 was considered as statistically significant publication bias.

\section{Results}

After importing results from five electronic databases and deleting duplicates, we found 1751 articles for title and abstract screening. We also found five additional articles by reading citations from the included studies and reviews. Following title and abstract screening step, we identified 39 potential articles to read full texts. We excluded 13 articles after carefully reading full texts, leaving 26 studies with a total of 8834 PTCs and 3127 FTCs that were included for final analysis $(5,7,8,9,10,18,19,20,21,22,23,24,25$, 26, 27, 28, 29, 30, 31, 32, 33, 34, 35, 36, 37, 38) (Fig. 1). Because HCC is considered a distinct variant of FTC in the WHO classification (3) and HCCs were only included in three studies by Van Heerden et al. (35), Ghossein et al. (24) and Xu et al. (38) respectively, the number of HCC cases was taken into account of FTC cases. Patients from

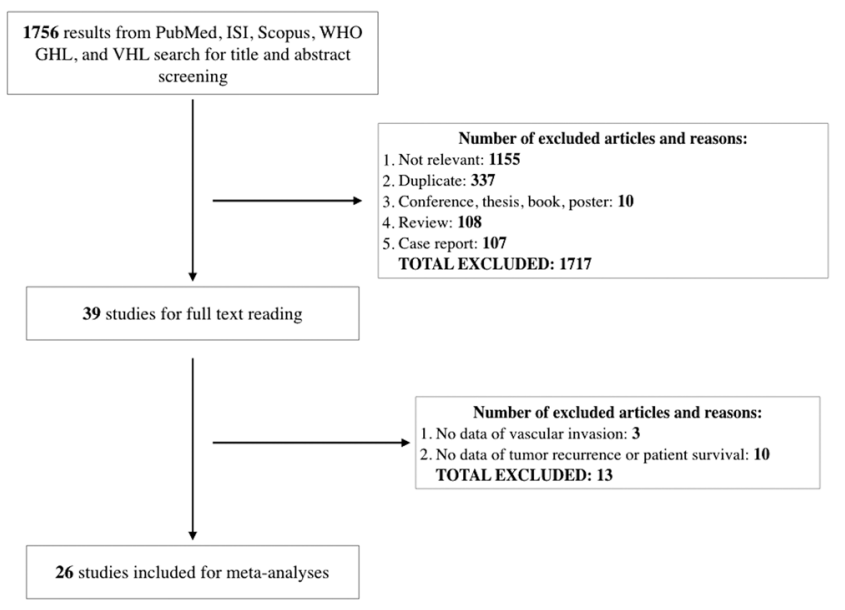

Figure 1

Study flowchart. VHL, Virtual Health Library; WHO GHL, World Health Organization Global Health Library. the studies by Kim et al. (26) and Ghossein et al. (24) could possibly overlap with patients from the studies by Kim et al. (8) and Xu et al. (38), respectively. We decided to select the study with higher number of cases for statistical analysis. Table 1 shows the detailed characteristics of each study.

For studies containing potential data, we contacted the authors via email to provide unreported HR and its 95\% CI for effects of VI on DSS and we received responses from Sweden, USA and Japan with adequate information for the meta-analysis $(32,33,38)$. Stenson et al. (32) and Sugino et al. (33) provided unadjusted HR and its 95\% CI of VI on DSS from their FTC series. We received data of unadjusted HR and its 95\% CI of VI on DSS in the study by Xu et al. (38) for the entire DTC population and subgroups of PTC and FTC.

\section{Impact of VI on tumor persistence}

We found separate data of tumor persistence in four of included studies, comprising 705 patients with DTCs. The pooled result demonstrated that VI was significantly associated with higher risk for tumor persistence $(\mathrm{OR}=2.75$; 95\% CI $=1.46-5.18$ ) (Fig. 2A). There was no heterogeneity across studies $\left(I^{2}=0 \%\right.$; p-heterogeneity $\left.=0.97\right)$.

\section{Impact of VI on LRR}

Separate data regarding impact of VI on LRR were found in ten studies, including 5018 patients with DTCs. In total, $15.6 \%$ DTC patients with VI and $2.7 \%$ of DTC patients without VI developed LRR during follow-up. DTCs with VI were associated with a significantly increased risk for $\mathrm{LRR}(\mathrm{OR}=4.44 ; 95 \% \mathrm{CI}=2.94-6.71)$ (Fig. 2B). Heterogeneity among included studies was not present $\left(I^{2}=0 \%\right.$; p-heterogeneity $\left.=0.60\right)$.

\section{Impact of VI on DR}

Ten studies comprising 1949 patients with DTCs provided relevant data regarding association of VI and DR. DR was identified in $13.9 \%$ and $2.2 \%$ of DTCs with and without VI during follow-up, respectively. The overall estimate showed a significant impact of VI on DR $(\mathrm{OR}=5.08$; 95\% CI $=2.95-8.75$ ) (Fig. 2C). Amount of heterogeneity among studies was low $\left(I^{2}=15 \%\right.$; p-heterogeneity $\left.=0.30\right)$. Excluding the study by $\mathrm{Xu}$ et al. (38) completely removed the heterogeneity among the included studies $\left(I^{2}=0 \%\right)$ 


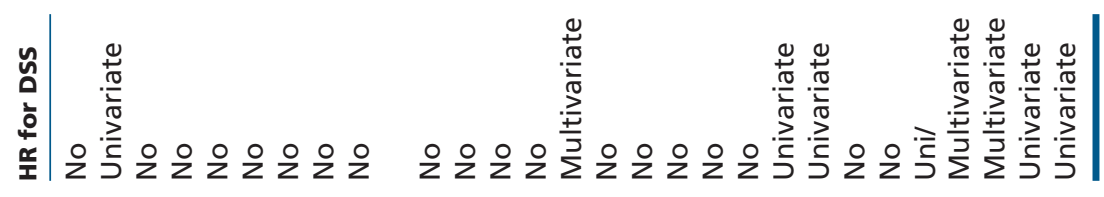

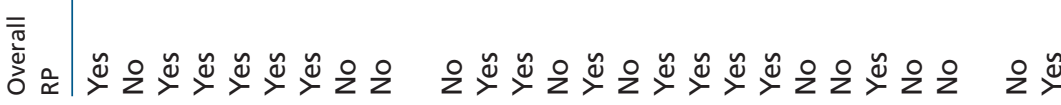

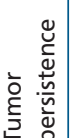

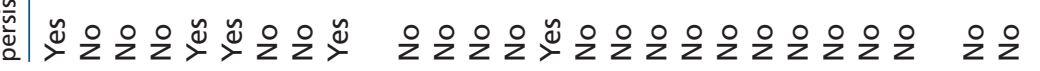

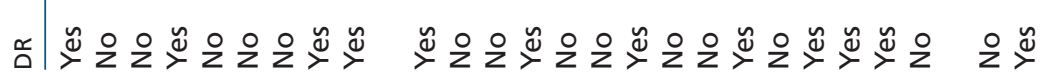

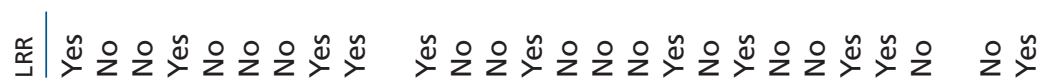

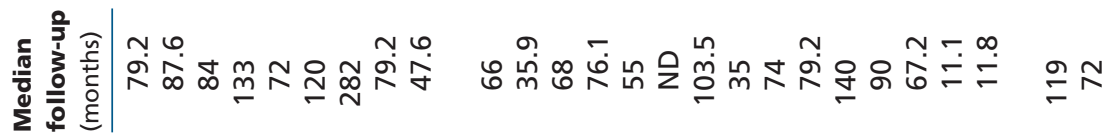

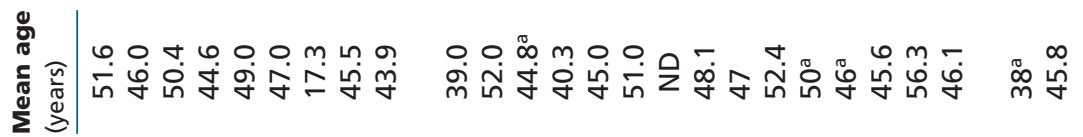

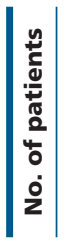

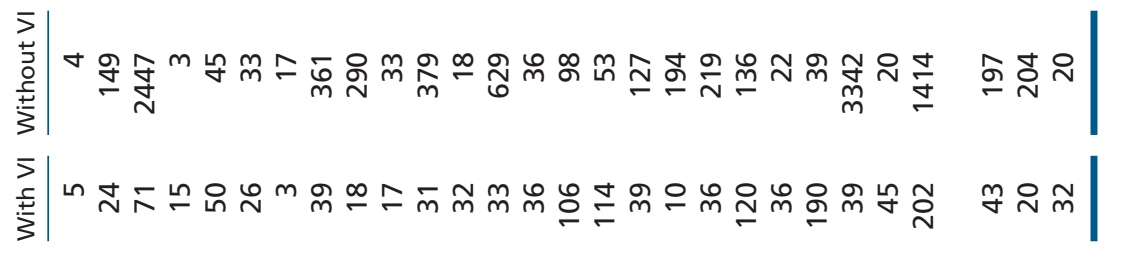
蒿

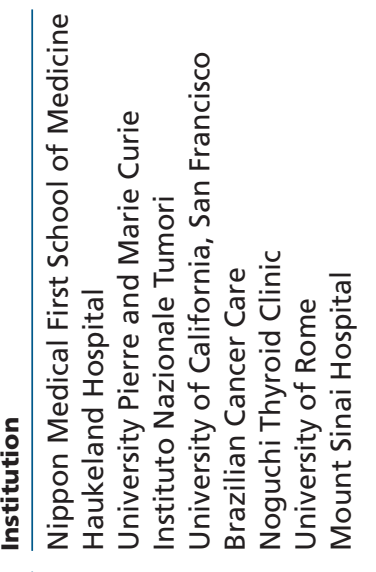

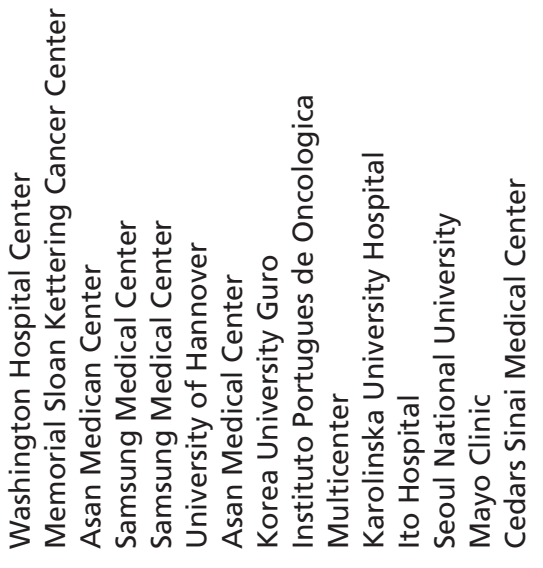
늠농난

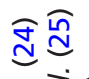

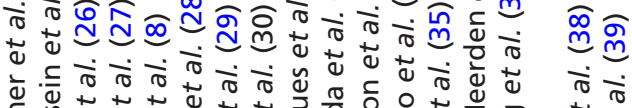

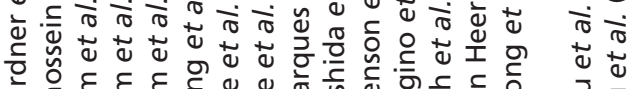

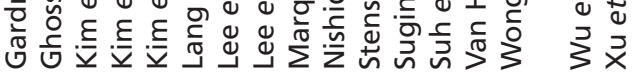


A

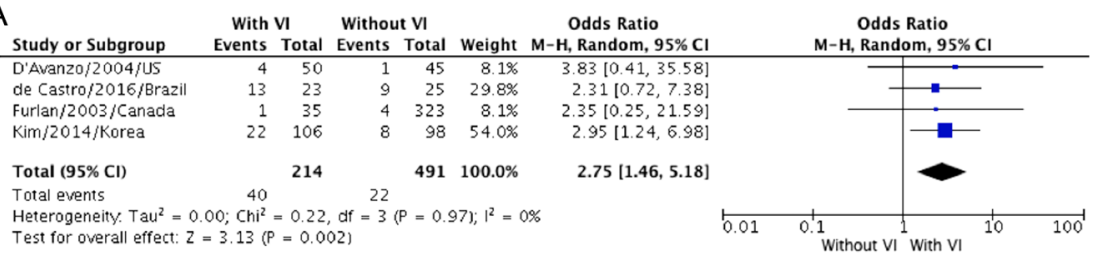

B

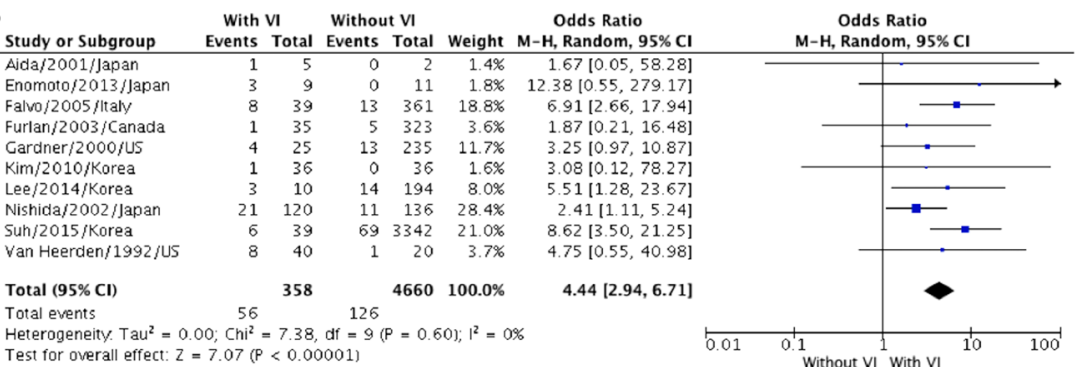

C

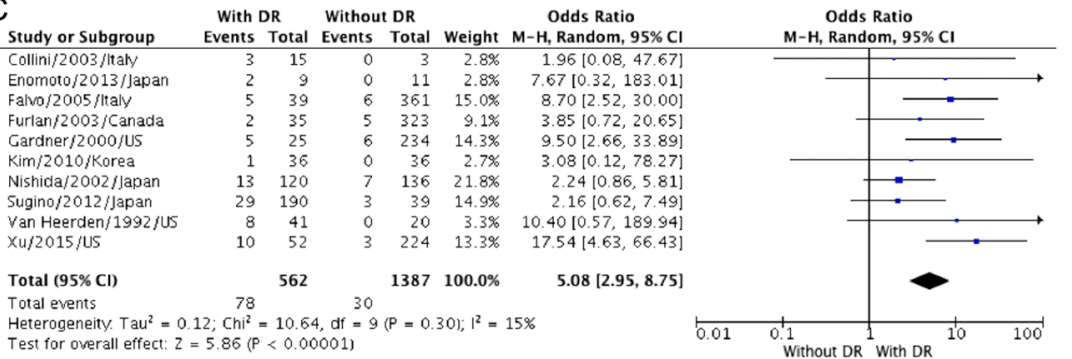

D

$\begin{array}{ccc}\text { With VI } & \text { Without VI } & \text { Odds Ratio } \\ \text { Events Total Events Total } & \text { Weight } & \text { M-H, Random, } \\ \text { Study or Subgroup } & & \end{array}$ Events Total Events Total Weight M-H, Random, $95 \% \mathrm{Cl} \quad \begin{gathered}\text { Odds Ratio } \\ \text { M-H, Random, }\end{gathered}$ Aida/2001/Japan Chereau/2016/France D'Avanzo/2004/Us de Castro/2016/Brazi Enomoto $2013 /$ baan Kim/2006/Korea Kim/2014/Korea Lee/2014/Kore Lee/2017/Kore Marques/2014/Portugal Nishida/2002/lapan
Suh/2015/Korea Xu/2015/U5

Total $(95 \% \mathrm{Cl})$ Total events $\begin{array}{rrrrr}1 & 5 & 0 & 2 & 1.9 \% \\ 2 & 71 & 59 & 2447 & 6.9 \%\end{array}$ $1.67[0.05,58.28]$
$1.17[0.28,4.90]$ $\begin{array}{rrrr}2447 & 6.9 \% & 1.17[0.28,4.90] \\ 0 & 3 & 2.3 \% & 1.96[0.08,47.67]\end{array}$ $8 \quad 24 \quad 6.4 \% \quad 0.60[0.13,2.81]$ $\begin{array}{rrrr}0 & 11 & 2.4 \% & 12.38[0.55,279.17] \\ 82 & 585 & 10.6 \% & 2.51[1.12,5.64]\end{array}$ $\begin{array}{rrrr}82 & 585 & 10.6 \% & 2.51[1.12,5.64] \\ 11 & 98 & 10.8 \% & 231[1.075 .02]\end{array}$ $\begin{array}{rrrr}1 & 98 & 10.8 \% & 2.31[1.07,5.02] \\ & 194 & 6.8 \% & 5.51[128,23.67]\end{array}$ $\begin{array}{rrrr}4 & 194 & 6.8 \% & 5.51[1.28,23.67] \\ 1 & 127 & 4.2 \% & 22.91[2.66,196.95]\end{array}$ $\begin{array}{rrrrr}1 & 127 & 4.2 \% & 22.91[2.66,196.95] \\ 21 & 219 & 10.7 \% & 8.44[3.81,18.66]\end{array}$ $20 \quad 136 \quad 11.8 \% \quad 2.29[1.24,4.26]$ $\begin{array}{llll}69 & 3342 & 10.0 \% & 8.62[3.50,21.25]\end{array}$ $3 \quad 224 \quad 7.4 \% \quad 17.54[4.63,66.43]$ $\begin{array}{ll}2.53 & 2.09,5.96]\end{array}$ Heterogeneity. $\mathrm{Tau}^{2}=0.51 ; \mathrm{Chi}^{2}=32.83, \mathrm{df}=13(\mathrm{P}=0.002) ; \mathrm{I}^{2}=60 \%$ Test for overall effect: $Z=4.70(P<0.00001)$ $3.53[2.09,5.96]$

E

Hazard Ratio
Study or Subgroup log[Hazard Ratiol \begin{tabular}{lrrrr} 
Study or Subgroup & log[Hazard Ratio] & SE & Weight & IV, Random, 95\% CI \\
\hline Akslen/1993/Nownay & 1.633 & 0.452 & $18.0 \%$ & $5.12[2.11,12.41]$
\end{tabular}

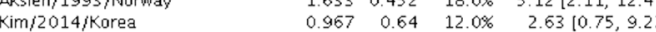
Stenson/2016/5weden $\quad \begin{array}{llllll}0.217 & 0.284 & 25.7 \% & 1.24[0.71,2.17]\end{array}$ $\begin{array}{llll}0.231 & 0.756 & 9.5 \% & 1.2610 .29,5.54]\end{array}$ wong/2013/U5 Wu/2014/U5 $\mathrm{Xu/2015/US}$ $\begin{array}{llll}0.833 & 0.337 & 23.1 \% & 2.30[1.19,4.45]\end{array}$ $\begin{array}{llll}2.104 & 0.816 & 8.5 \% & 8.20[1.66,40.58]\end{array}$ $\begin{array}{llll}1.439 & 1.415 & 3.3 \% & 4.22[0.26,67.51]\end{array}$

Total $(95 \% \mathrm{CI})$ $100.0 \% \quad 2.47[1.45,4.21]$

Heterogeneity, $\mathrm{Tau}^{2}=0.21 ; \mathrm{Ch} \mathbf{l}^{2}=10.97$, df $=6(\mathrm{P}=0.09) ; \mathrm{I}^{2}=45 \%$

Test for overall effect: $Z=3.33(P=0.0009)$

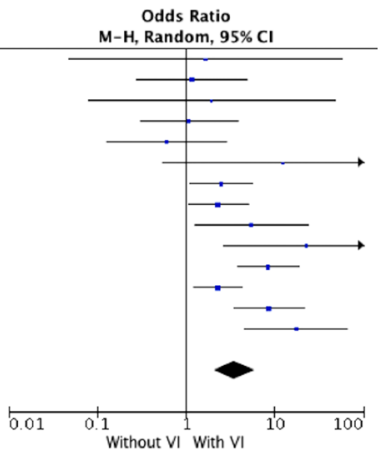

and the significant effect remained unaffected $(\mathrm{OR}=4.08$; $95 \% \mathrm{CI}=2.44-6.82$ ).

\section{Impact of VI on overall RP}

We found 14 studies with 8053 DTC patients reporting relevant information of the association of VI and overall

Hazard Ratio IV, Random, $95 \% \mathrm{CI}$

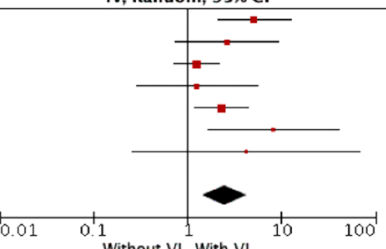

\section{Figure 2}

Forest plots of association of vascular invasion with $(A)$ tumor persistence; (B) locoregional recurrence; (C) distant recurrence; $(D)$ overall recurrence/ persistence and $(E)$ hazard ratio for disease-specific survival.
RP. The pooled estimate demonstrated that VI significantly increased the risk for overall RP $(\mathrm{OR}=3.53$; 95\% CI $=2.09$ 5.96) (Fig. 2D). The degree of heterogeneity across studies was high $\left(I^{2}=60 \%\right.$; p-heterogeneity $\left.<0.0001\right)$. It remained significant after removing each of included studies at a time but the statistical significance of effects was unaffected. The significant between-study heterogeneity 
Table 2 Pooled results of subgroup analysis for tumor recurrence.

\begin{tabular}{|c|c|}
\hline Subgroup & No. of studies \\
\hline \multicolumn{2}{|l|}{ PTC } \\
\hline LRR & 5 \\
\hline DR & 3 \\
\hline Tumor persistence & 2 \\
\hline Overall RP & 6 \\
\hline \multicolumn{2}{|l|}{ FTC } \\
\hline LRR & 5 \\
\hline DR & 7 \\
\hline Tumor persistence & 3 \\
\hline Overall RP & 6 \\
\hline
\end{tabular}

\begin{tabular}{c}
\hline No. of patients \\
\hline 4553 \\
967 \\
356 \\
7011 \\
209 \\
606 \\
349 \\
510 \\
\hline
\end{tabular}

\begin{tabular}{l}
\hline OR \\
\hline \\
\hline \\
\hline \\
8.95 \\
2.71 \\
3.36 \\
4.73 \\
3.76 \\
2.78 \\
2.76
\end{tabular}

\begin{tabular}{l}
\hline \multicolumn{1}{c}{$\mathbf{9 5 \% \mathrm { Cl }}$} \\
\hline \\
$3.51-10.08$ \\
$3.46-18.98$ \\
$0.98-7.80$ \\
$1.49-7.59$ \\
$1.28-17.45$ \\
$1.67-8.47$ \\
$1.27-6.07$ \\
$1.17-6.53$ \\
\hline
\end{tabular}

\begin{tabular}{|c|c|}
\hline$P$ value & $P^{2}(\%)$ \\
\hline$<0.0001$ & 0 \\
\hline$<0.0001$ & 0 \\
\hline 0.05 & 0 \\
\hline 0.004 & 71 \\
\hline 0.02 & 0 \\
\hline 0.001 & 0 \\
\hline 0.01 & 0 \\
\hline 0.02 & 28 \\
\hline
\end{tabular}

$\mathrm{Cl}$, confidence interval; DR, distant recurrence; FTC, follicular thyroid carcinoma; LRR, locoregional recurrence; OR, odds ratio; PTC, papillary thyroid carcinoma; $\mathrm{RP}$, recurrence/persistence.

was caused mainly by the studies by Marques et al. (30), $\mathrm{Xu}$ et al. (38) and Suh et al. (34). Excluding these three studies simultaneously resulted in completely removing the heterogeneity among included studies $\left(I^{2}=0 \%\right.$; p-heterogeneity $=0.59$ ) and the overall effect slightly decreased but remained significant (OR=2.11; 95\% $\mathrm{CI}=1.49-3.00)$.

\section{Impact of VI on DSS}

In 26 included studies, we found relevant data of HR for DSS or sufficient data to estimate HR for DSS in only four studies $(5,8,36,37)$. We received three replies from USA, Sweden and Japan containing adequate data on unadjusted HR for DSS for the pooled analysis (32, 33, 38). We used random effect model weighted by inverse variance method to pool HR for DSS and the pooled result demonstrated that VI significantly increased the risk of disease-related mortality in DTC patients with VI compared with DTC patients without VI $(\mathrm{HR}=2.47 ; 95 \%$ $\mathrm{CI}=1.45-4.21$ ) (Fig. 2E). There was a moderate amount of heterogeneity between the included studies $\left(I^{2}=45 \%\right.$; p-heterogeneity=0.09). After excluding the study by Stenson et al. (32), there was no heterogeneity among the studies $\left(I^{2}=0 \%\right.$; p-heterogeneity $\left.=0.42\right)$ and the pooled estimate remained significant with an increased effect size $(\mathrm{HR}=3.02 ; 95 \% \mathrm{CI}=1.94-4.68)$.

\section{Subgroup analyses}

To further explore the sources of heterogeneity among studies, we performed subgroup analysis with regard to the impact of VI on recurrence and survival in PTC and FTC subgroup. Association of LRR, DR and overall RP with VI in each subgroup is summarized in Table 2.

In PTCs, the pooled results showed that VI significantly increased the risk of LRR, DR and overall RP. However, VI was not associated with a higher risk for tumor persistence (Table 2 and Supplementary Fig. 1, see section on supplementary data given at the end of this article). In FTC subgroup, effects of VI on tumor persistence, LRR, DR and overall RP were all associated with a significantly increased risk (Table 2 and Supplementary Fig. 2).

We carried out an additional analysis to further examine the prognostic effect of extensive VI $(\geq 4$ VI foci) in FTCs and found eligible data in four studies (9, $27,28,38)$. Our results demonstrated that the presence of extensive VI increases the risk for DR 26 times as compared with FTCs with focal VI (<4 VI foci) (OR=26.38; 95\% $\left.\mathrm{CI}=7.67-90.78 ; I^{2}=54 \%\right)$.

Table 3 Pooled results of subgroup analysis for DSS.

\begin{tabular}{l}
\hline Subgroup \\
\hline HR calculation method \\
Unadjusted HR \\
Adjusted HR \\
Histologic type \\
PTC \\
FTC \\
MIFTC
\end{tabular}

\begin{tabular}{c} 
No. of studies \\
\hline 5 \\
3 \\
3 \\
4 \\
3 \\
\hline
\end{tabular}

\begin{tabular}{c}
\hline No. of patients \\
\hline 2358 \\
2066 \\
637 \\
543 \\
452 \\
\hline
\end{tabular}

\begin{tabular}{c}
\hline HR for DSS \\
\hline 2.16 \\
2.75 \\
\\
5.70 \\
1.38 \\
1.70 \\
\hline
\end{tabular}

\begin{tabular}{ccc}
\hline $95 \% \mathbf{C l}$ & & $\boldsymbol{I}^{\mathbf{2}(\%)}$ \\
\cline { 1 - 1 } $1.19-3.91$ & & 50 \\
$1.44-5.25$ & & 12 \\
& \\
$2.63-12.37$ & & 0 \\
$0.87-2.21$ & & 0 \\
$0.64-4.52$ & 50 \\
\hline
\end{tabular}

$\mathrm{Cl}$, confidence interval; FTC, follicular thyroid carcinoma; HR, hazard ratio; MIFTC, minimally invasive follicular thyroid carcinoma; PTC, papillary thyroid carcinoma. 
Subgroup analyses for DSS were also performed by HR calculation method (unadjusted HR and adjusted HR) and histologic type (PTC, entire FTC population and minimally invasive FTC (MIFTC)). Subgroups of unadjusted and adjusted HR both showed significantly adverse effects of VI on DSS (Table 3). When histologically dividing into subgroups of PTC and FTC, only the pooled result of PTC was associated with worse impact on DSS. On the other hand, in subgroups of FTC and MIFTC, VI showed no significant effect on DSS (Table 3 and Supplementary Fig. 3). Between-study heterogeneity

Table 4 Newcastle-Ottawa quality assessment scale for cohort studies.

\begin{tabular}{|c|c|c|c|c|}
\hline \multirow[b]{2}{*}{ Author } & \multicolumn{3}{|c|}{$\begin{array}{l}\text { Number of stars awarded in } \\
\text { each domain }\end{array}$} & \multirow[b]{2}{*}{ Study quality } \\
\hline & Selection & Comparability & Outcome & \\
\hline Aida et al. (18) & 3 & 0 & 3 & Moderate \\
\hline $\begin{array}{l}\text { Akslen et al. } \\
\text { (19) }\end{array}$ & 3 & 1 & 3 & High \\
\hline $\begin{array}{l}\text { Chereau et al. } \\
\text { (20) }\end{array}$ & 3 & 0 & 3 & Moderate \\
\hline Collini et al. (9) & 3 & 0 & 3 & Moderate \\
\hline $\begin{array}{l}\text { D'Avanzo et al. } \\
\text { (21) }\end{array}$ & 3 & 0 & 3 & Moderate \\
\hline $\begin{array}{l}\text { de Castro et al. } \\
\text { (22) }\end{array}$ & 3 & 0 & 3 & Moderate \\
\hline $\begin{array}{l}\text { Enomoto et al. } \\
\text { (23) }\end{array}$ & 3 & 0 & 3 & Moderate \\
\hline Falvo et al. (10) & 3 & 1 & 3 & High \\
\hline Furlan et al. (7) & 3 & 0 & 2 & Low \\
\hline $\begin{array}{l}\text { Gardner et al. } \\
\text { (24) }\end{array}$ & 3 & 1 & 3 & High \\
\hline $\begin{array}{l}\text { Ghossein et al. } \\
\text { (25) }\end{array}$ & 3 & 0 & 3 & Moderate \\
\hline Kim et al. (26) & 3 & 0 & 3 & Moderate \\
\hline Kim et al. (27) & 3 & 0 & 3 & Moderate \\
\hline Kim et al. (8) & 3 & 0 & 3 & Moderate \\
\hline Lang et al. (28) & 3 & 0 & 3 & Moderate \\
\hline Lee et al. (29) & 3 & 0 & 3 & Moderate \\
\hline Lee et al. (30) & 3 & 0 & 2 & Low \\
\hline $\begin{array}{l}\text { Marques et al. } \\
\text { (31) }\end{array}$ & 3 & 0 & 3 & Moderate \\
\hline $\begin{array}{l}\text { Nishida et al. } \\
\text { (32) }\end{array}$ & 3 & 0 & 3 & Moderate \\
\hline $\begin{array}{l}\text { Stenson et al. } \\
\text { (33) }\end{array}$ & 3 & 0 & 3 & Moderate \\
\hline $\begin{array}{l}\text { Sugino et al. } \\
\text { (34) }\end{array}$ & 3 & 0 & 3 & Moderate \\
\hline Suh et al. (35) & 3 & 0 & 3 & Moderate \\
\hline $\begin{array}{l}\text { Van } \\
\text { Heerden et al. } \\
\text { (36) }\end{array}$ & 3 & 0 & 3 & Moderate \\
\hline $\begin{array}{l}\text { Wong et al. } \\
\text { (37) }\end{array}$ & 3 & 0 & 3 & Moderate \\
\hline Wu et al. (38) & 3 & 2 & 3 & High \\
\hline Xu et al. (39) & 3 & 0 & 3 & Moderate \\
\hline
\end{tabular}

significantly decreased and was almost absent in subgroup analyses.

\section{Risk of bias assessment and quality of studies}

All included studies were retrospective studies. The number of stars awarded to each of included studies ranged from five to eight stars. All studies but two were considered to be of moderate to high quality. Details of given stars within domains of Selection, Comparability and Outcome for all included studies were described in Table 4.

\section{Publication bias}

Egger's regression test and funnel plot were used to examine the presence of publication bias. Observation of funnel plots did not reveal strong indication of publication bias among the set of studies included in the meta-analyses. Egger's regression test of all effects did not suggest any evidence of publication bias (data not shown). We did not analyze publication bias among subgroups because this methods is known to be unreliable for meta-analyses of small numbers of included studies (39).

\section{Discussion}

DTC is the major histologic type and accounts for more than 95\% of thyroid cancer (3). Most of DTCs generally show good response to initial treatment. However, a subset of DTCs behave aggressively, develop metastases or recurrence and are associated with a higher rate of mortality. There have been a number of studies investigating the prognostic factors for DTCs, and some factors have been proposed as adverse prognostic factors such as age over 45 , tumor size exceeding $4 \mathrm{~cm}$, the presence of extrathyroidal extension, lymph node metastasis and distant metastasis $(5,40,41)$. The role of VI to predict adverse outcome in DTC has been an ongoing debate $(5,8,32,38,40,41)$. Our study is the first meta-analysis to help clarify this debate and confirm the prognostic implication of VI in DTCs.

In our study, we comprehensively reviewed five electronic databases and investigated the association of VI with DTC patient outcomes. Our results demonstrate that the presence of VI in DTCs is not only associated with an increased risk for tumor recurrence or persistence but also significantly associated with an adverse impact on patient DSS. Our findings strongly support the latest ATA guidelines in which DTCs with VI are classified 
as ATA intermediate risk, while DTCs without VI are regarded as ATA low risk (42). However, the three-tiered ATA classification did not specifically address the risk of tumor recurrence associated with each histologic type. In subgroup analysis of our meta-analysis, the presence of VI is both associated with a significantly increased risk for LRR, DR and overall RP in both PTC and FTC patients (Table 2). As a result, pathologists should assess the presence and extent of VI in all specimen blocks during histopathological examination because the presence of even one focus of VI can enhance the recurrence risk for patients and influence the management and follow-up schedule. The risk for tumor persistence is heterogeneous between histologic subgroups with the insignificant pooled results in patients with PTC. But, this result should be interpreted with caution because of the small number of included studies and patients (Table 2).

In addition to the presence of VI, the extent of VI (number of VI foci) also merits concern from thyroid specialists. A few studies reported that FTCs with a greater extent of VI ( $\geq 4$ foci of VI) are associated with poorer outcome $(24,38,43)$. Our results demonstrated that FTCs with extensive VI ( $\geq 4$ VI foci) are associated with a significantly increased risk for distant metastasis during follow-up as compared to tumors with focal VI ( $<4$ foci). In the ATA 2009 guidelines, the degree of VI in FTC was not included in the risk stratification system (44). But, this prognostic variable was supplemented in the ATA 2015 guidelines in which FTCs with extensive VI ( $\geq 4$ VI foci) are classified as ATA high risk (42). Our results further support the latest ATA guidelines and warrant the need of careful evaluation for the presence and degree of VI in thyroid cancer.

Our primary and subgroup analyses also indicate that the presence of VI in DTCs is an independent and adverse risk factor on DTC patients' survival (Table 3). The significant overall estimate of HR for DSS is mostly attributable to the PTC population. When we separate into each histologic subgroup, there are heterogeneities in pooled results regarding impact of VI on DSS. The presence of VI is only associated with a significantly unfavorable effect on DSS in PTC patients, but this effect is not significant in FTC patients (Table 3). The different criteria in diagnosis of PTC and FTC might be an appropriate explanation for this difference. In previous years before the latest consensus regarding new term of 'non-invasive follicular thyroid neoplasm with papillarylike nuclear features (NIFTP)' (45), the diagnosis of PTC mostly relies on the characteristic nuclear features and many cases of non-invasive encapsulated follicular variant PTCs (FVPTC) might be included in PTC series in our study. Meanwhile, the presence of at least VI and/ or capsular invasion is required for the diagnosis of FTC. Hence, the survival of patients in group of PTCs without VI might be much better than patients in group of PTCs with VI and results in higher HR ratio in PTC subgroup.

Kim et al. (8) found an association of VI with increased mortality rate in minimally invasive but not in widely invasive FTCs and suggested that MIFTC be separated into two groups according to the presence or absence of VI. This finding, however, was not found in other MIFTC series $(32,33)$, and our pooled analysis could not establish a significant association between VI and poorer outcome in MIFTCs (Table 3). Although our pooled analysis indicates an insignificant effect of VI on FTC patient's survival, the presence and extent of VI in FTCs do need to be carefully examined and reported in histopathological report due to its significant association with increased risk for tumor recurrence or persistence in FTCs.

The diagnosis of microscopic VI has been an ongoing controversyin surgical histopathology anditis an important criterion in the diagnosis of FTC (3). Classic criteria for diagnosis of microscopic VI have been well described previously $(3,46,47)$, and these strict criteria should be used for the diagnosis of VI on routine histopathological examination to avoid artifactual displacement of tumor cells (47). Our study has a limitation that not all included studies reported or described the criteria for diagnosis of VI and it could raise heterogeneity among the included studies. Nonetheless, the significant heterogeneity among included studies of the overall effects are present in only a few of pooled results and the pooled results remain statistically significant following the sensitivity analysis, thus reflecting a good stability of our analyses. Another limitation is that all of included studies were retrospective studies so selection biases are inevitable.

To summarize, our current study demonstrated the prognostic importance of VI as a predictor of tumor recurrence in both PTCs and FTCs and its association with unfavorable patient outcomes in PTCs. The presence and extent of VI in DTCs should be considered an adverse prognostic factor and needs to be carefully assessed on histopathological examination for accurate risk stratification, management and follow-up.

\section{Supplementary data}

This is linked to the online version of the paper at http://dx.doi.org/10.1530/ EJE-17-0260. 
Declaration of interest

The authors declare that there is no conflict of interest that could be perceived as prejudicing the impartiality of this study.

\section{Funding}

This research did not receive any specific grant from any funding agency in the public, commercial or not-for-profit sector.

\section{Acknowledgements}

The authors specially thank Dr Inga-Lena Nilsson (Karolinska University Hospital, Sweden), Dr Ronald Ghossein, Dr Bin Xu (Memorial Sloan Kettering Cancer Center, USA) and Dr Kiminori Sugino (Ito Hospital, Japan) for their generous help to calculate necessary data for pooled analysis.

\section{References}

1 Davies L \& Welch HG. Current thyroid cancer trends in the United States. JAMA Otolaryngology: Head and Neck Surgery 2014140 317-322. (doi:10.1001/jamaoto.2014.1)

2 Kilfoy BA, Zheng T, Holford TR, Han X, Ward MH, Sjodin A, Yaqun Z, Bai Y, Zhu C, Guo GL et al. International patterns and trends in thyroid cancer incidence, 1973-2002. Cancer Causes and Control 2009 20 525-531. (doi:10.1007/s10552-008-9260-4)

3 De Lellis, Lloyd R, Heitz P \& Eng C. World Health Organization classifcation of tumours. In Pathology and Genetics of Tumours of Endocrine Organs. Lyon, France: IARC Press, 2004.

4 Lerch H, Schober O, Kuwert T \& Saur HB. Survival of differentiated thyroid carcinoma studied in 500 patients. Journal of Clinical Oncology 199715 2067-2075. (doi:10.1200/JCO.1997.15.5.2067)

5 Akslen LA, Myking AO, Salvesen H \& Varhaug JE. Prognostic importance of various clinicopathological features in PTC. European Journal of Cancer 1992 29A 44-51. (doi:10.1016/0959. 8049(93)90574-y)

6 Cao J, Hu JL, Chen C, Wang QL, Fang XH, Zhang Y \& Ge MH Vascular invasion is an independent prognostic factor for distant recurrence-free survival in papillary thyroid carcinoma: a matchedcase comparative study. Journal of Clinical Pathology 201669 872-877. (doi: 10.1136/jclinpath-2015-203547)

7 Furlan JC, Bedard YC \& Rosen IB. Clinicopathologic significance of histologic vascular invasion in papillary and follicular thyroid carcinomas. Journal of the American College of Surgeons 2004198 341-348. (doi:10.1016/j.jamcollsurg.2003.11.012)

8 Kim HJ, Sung JY, Oh YL, Kim JH, Son YI, Min YK, Kim SW \& Chung JH Association of vascular invasion with increased mortality in patients with minimally invasive follicular thyroid carcinoma but not widely invasive follicular thyroid carcinoma. Head and Neck 201436 1695-1700. (doi:10.1002/hed.23511)

9 Collini P, Sampietro G \& Pilotti S. Extensive vascular invasion is a marker of risk of relapse in encapsulated non-Hurthle cell follicular carcinoma of the thyroid gland: a clinicopathological study of 18 consecutive cases from a single institution with a 11-year median follow-up. Histopathology 200444 35-39. (doi:10.1111/j.13652559.2004.01729.x)

10 Falvo L, Catania A, D'Andrea V, Marzullo A, Giustiniani MC \& De Antoni E. Prognostic importance of histologic vascular invasion in papillary thyroid carcinoma. Annals of Surgery 2005241 640-646. (doi:10.1097/01.sla.0000157317.60536.08)

11 Moher D, Liberati A, Tetzlaff J, Altman DG \& PRISMA Group. Preferred Reporting Items for Systematic Reviews and Meta-Analyses:
The PRISMA Statement. PLoS Medicine 20096 e1000097. (doi:10.1371/ journal.pmed.1000097)

12 Wells GA, Shea B \& O'Connel D. The Newcastle-Ottawa Scale (NOS) for Assessing the Quality of Nonrandomised Studies in Meta-Analyses. Ottawa: Ottawa Hospital Institute, 2011.

13 Higgins JP \& Green S (eds). Cochrane Handbook for Systematic Reviews of Interventions. West Sussex, England: John Wiley \& Sons, 2008.

14 Tierney JF, Stewart LA, Ghersi D, Burdett S \& Sydes MR. Practical methods for incorporating summary time-to-event data into metaanalysis. Trials 20078 16. (doi:10.1186/1745-6215-8-16)

15 Higgins JP \& Thompson SG. Quantifying heterogeneity in a metaanalysis. Statistics in Medicine 200221 1539-1558. (doi:10.1002/ sim.1186)

16 Ioannidis JP, Patsopoulos NA \& Evangelou E. Uncertainty in heterogeneity estimates in meta-analyses. BMJ 2007335 914-916. (doi:10.1136/bmj.39343.408449.80)

17 Hamilton WK, Aydin B \& Mizumoto A. MAVIS: Meta Analysis via Shiny. R package version 1.1.2, 2016. (Available at http:// kylehamilton.net/shiny/MAVIS/)

18 Aida N, Yamada N, Asano G \& Tanaka S. 3-D analysis of vascular and capsular invasion in thyroid follicular carcinoma. Pathology International 200151 425-430. (doi:10.1046/j.14401827.2001.01221.x)

19 Chereau N, Tresallet C, Noullet S, Godiris-Petit G, Tissier F, Leenhardt L \& Menegaux F. Does the T1 subdivision correlate with the risk of recurrence of papillary thyroid cancer? Langenbeck's Archives of Surgery 2016401 223-230. (doi:10.1007/s00423-016-1399-y)

20 D'Avanzo A, Treseler P, Ituarte PH, Wong M, Streja L, Greenspan FS, Siperstein AE, Duh QY \& Clark OH. Follicular thyroid carcinoma: histology and prognosis. Cancer 2004100 1123-1129. (doi:10.1002/ cncr.20081)

21 de Castro TP, Waissmann W, Simoes TC, de Mello RC \& Carvalho DP. Predictors for papillary thyroid cancer persistence and recurrence: a retrospective analysis with a 10-year follow-up cohort study. Clinical Endocrinology 201685 466-474. (doi:10.1111/cen.13032)

22 Enomoto K, Enomoto Y, Uchino S, Yamashita H \& Noguchi S. Follicular thyroid cancer in children and adolescents: clinicopathologic features, long-term survival, and risk factors for recurrence. Endocrine Journal 201360 629-635. (doi:10.1507/endocrj. EJ12-0372)

23 Gardner RE, Tuttle RM, Burman KD, Haddady S, Truman C, Sparling YH, Wartofsky L, Sessions RB \& Ringel MD. Prognostic importance of vascular invasion in papillary thyroid carcinoma. Archives of Otolaryngology: Head and Neck Surgery 2000126 309-312. (doi:10.1001/archotol.126.3.309)

24 Ghossein RA, Hiltzik DH, Carlson DL, Patel S, Shaha A, Shah JP, Turtle RM \& Singh B Prognostic factors of recurrence in encapsulated Hurthle cell carcinoma of the thyroid gland: a clinicopathologic study of 50 cases. Cancer 2006106 1669-1676. (doi:10.1002/ cncr.21825)

25 Kim JM, Kim TY, Kim WB, Gong G, Kim SC, Hong SJ \& Shong YK. Lymphovascular invasion is associated with lateral cervical lymph node metastasis in papillary thyroid carcinoma. Laryngoscope 2006 116 2081-2085. (doi:10.1097/01.mlg.0000242118.79647.a9)

26 Kim WW, Hur SM, Kim SH, Lee SK, Kim S, Oh YL, Choe JH, Lee JE, Kim JH, Nam SJ et al. Prognostic factors and treatment in follicular thyroid carcinoma. Journal of the Korean Surgical Society 201078 149-156. (doi:10.4174/jkss.2010.78.3.149)

27 Lang W, Choritz H \& Hundeshagen H. Risk factors in follicular thyroid carcinomas. A retrospective follow-up study covering a 14-year period with emphasis on morphological findings. American Journal of Surgical Pathology 198610 246-255. (doi:10.1097/00000478198604000-00003) 
28 Lee YM, Lee YH, Song DE, Kim WB, Sung TY, Yoon JH, Chung KW $\&$ Hong SJ. Prognostic impact of further treatments on distant metastasis in patients with minimally invasive follicular thyroid carcinoma: verification using inverse probability of treatment weighting. World Journal of Surgery 201741 1144. (doi:10.1007/ s00268-017-3879-9)

29 Lee E, Jung W, Woo JS, Lee JB, Shin BK, Kim HK, Kim A \& Kim BH. Tumor sprouting in papillary thyroid carcinoma is correlated with lymph node metastasis and recurrence. Korean Journal of Pathology 201448 117-125. (doi:10.4132/KoreanJPathol.2014.48.2.117)

30 Marques P, Leite V \& Bugalho MJ. Retrospective analysis of 255 papillary thyroid carcinomas $</=2 \mathrm{~cm}$ : clinicohistological features and prognostic factors. European Thyroid Journal 20143 258-263. (doi:10.1159/000369133)

31 Nishida T, Katayama SI \& Tsujimoto M. The clinicopathological significance of histologic vascular invasion in differentiated thyroid carcinoma. American Journal of Surgery 2002183 80-86. (doi:10.1016/ S0002-9610(01)00843-1)

32 Stenson G, Nilsson IL, Mu N, Larsson C, Lundgren CI, Juhlin CC, Hoog A \& Zedenius J. Minimally invasive follicular thyroid carcinomas: prognostic factors. Endocrine $2016 \mathbf{5 3}$ 505-511. (doi:10.1007/s12020-016-0876-y)

33 Sugino K, Kameyama K, Ito K, Nagahama M, Kitagawa W, Shibuya H, Ohkuwa K, Yano Y, Uruno T, Akaishi J et al. Outcomes and prognostic factors of 251 patients with minimally invasive follicular thyroid carcinoma. Thyroid 201222 798-804. (doi:10.1089/thy.2012.0051)

34 Suh YJ, Kwon H, Kim SJ, Choi JY, Lee KE, Park YJ, Park DJ \& Youn YK. Factors affecting the locoregional recurrence of conventional papillary thyroid carcinoma after surgery: a retrospective analysis of 3381 patients. Annals of Surgical Oncology 201522 3543-3549. (doi:10.1245/ s10434-015-4448-9)

35 van Heerden JA, Hay ID, Goellner JR, Salomao D, Ebersold JR, Bergstralh EJ \& Grant CS. Follicular thyroid carcinoma with capsular invasion alone: a nonthreatening malignancy. Surgery 1992112 1130-1136; discussion 1136-1138.

36 Wong RM, Bresee C \& Braunstein GD. Comparison with published systems of a new staging system for papillary and follicular thyroid carcinoma. Thyroid 201323 566-574. (doi:10.1089/thy.2012.0181)

37 Wu M-H, Shen WT, Gosnell J \& Duh Q-Y. Prognostic significance of extranodal extension of regional lymph node metastasis in papillary thyroid cancer. Head and Neck 201537 1336-1343. (doi:10.1002/ hed.23747)

38 Xu B, Wang L, Tuttle RM, Ganly I \& Ghossein R. Prognostic impact of extent of vascular invasion in low-grade encapsulated follicular cell-derived thyroid carcinomas: a clinicopathologic study of 276 cases. Human Pathology 201546 1789-1798. (doi:10.1016/j. humpath.2015.08.015)

39 Ioannidis JP \& Trikalinos TA. The appropriateness of asymmetry tests for publication bias in meta-analyses: a large survey. CMAJ $2007 \mathbf{1 7 6}$ 1091-1096. (doi:10.1503/cmaj.060410)

40 Shah JP, Loree TF, Dharker DF, Strong EF, Begg CF \& Vlamis V. Prognostic factors in differentiated carcinoma of the thyroid gland. American Journal of Surgery 1992164 658-661. (doi: 10.1016/S00029610(05)80729-9)

41 Loree TR. Therapeutic implications of prognostic factors in differentiated carcinoma of the thyroid gland. Seminars in Surgical Oncology 199511 246-255. (doi:10.1002/ssu.2980110310)

42 Haugen BR, Alexander EK, Bible KC, Doherty GM, Mandel SJ, Nikiforov YE, Pacini F, Randolph GW, Sawka AM, Schlumberger M et al. 2015 American Thyroid Association Management Guidelines for Adult Patients with Thyroid Nodules and Differentiated Thyroid Cancer: The American Thyroid Association Guidelines Task Force on Thyroid Nodules and Differentiated Thyroid Cancer. Thyroid 201626 1-133. (doi: 10.1089/thy.2015.0020)

43 O’Neill CJ, Vaughan L, Learoyd DL, Sidhu SB, Delbridge LW \& Sywak MS. Management of follicular thyroid carcinoma should be individualized based on degree of capsular and vascular invasion. Annals of Surgical Oncology 201137 181-185. (doi: 10.1016/j. ejso.2010.11.005)

44 Puxeddu E \& Filetti S. The 2009 American Thyroid Association Guidelines for management of thyroid nodules and differentiated thyroid cancer: progress on the road from consensus- to evidencebased practice. Thyroid 200919 1145-1147. (doi:10.1089/ thy.2009.1601)

45 Nikiforov YE, Seethala RR, Tallini G, Baloch ZW, Basolo F, Thompson LD, Barletta JA, Wenig BM, Al Ghuzlan A, Kakudo K et al. Nomenclature revision for encapsulated follicular variant of papillary thyroid carcinoma: a paradigm shift to reduce overtreatment of indolent tumors. JAMA Oncology 20162 1023-1029. (doi:10.1001/ jamaoncol.2016.0386)

46 Nikiforov YE, Biddinger PW \& Thompson LD (eds). Diagnostic Pathology and Molecular Genetics of the Thyroid: A Comprehensive Guide for Practicing Thyroid Pathology. Philadelphia, Pennsylvania: Lippincott Williams \& Wilkins, 2012.

47 Mete O \& Asa SL. Pathological definition and clinical significance of vascular invasion in thyroid carcinomas of follicular epithelial derivation. Modern Pathology 201124 1545-1552. (doi:10.1038/ modpathol.2011.119)

Received 30 March 2017

Revised version received 15 May 2017

Accepted 30 May 2017 